\title{
Diversity in Indian Infrastructure Organizations and the Maze of Empowerment
}

\author{
Deepika Pandita, Hemendra Shribatho, Sampurna Ray
}

\begin{abstract}
This paper attempts to examine women empowerment practices and the drivers of successful women empowerment initiatives in Indian infrastructure organizations, so as to aid readers in understanding how these initiatives and practices may be optimized for the benefit of better performance management and employee engagement. We have based this paper on a systematic review of literature which seeks to examine the modern thought process and evidence. Emphasis is drawn specifically on reviewing the HR practices of current employers to empower the women in the workforce. Our paper concludes that ensuring that an initiative is crafted to an organization's and its employees' needs makes for efficient empowerment initiatives that leave a sustainable impact on the performance, productivity and engagement levels of its beneficiaries and the organization as a whole.
\end{abstract}

Keywords: Empowerment, Gender, Talent, Human Resources, Employee Engagement

\section{INTRODUCTION}

Women empowerment initiatives targeted at engaging women and increasing their participation at the workplace have also been specifically aimed at women in leadership. These initiatives have been a step forward in the direction of gender parity in the corporate context, and in the social context as well. Defending the rights and entitlement of women, professional development \& growth, empowering the voice of women and enabling them to share their opinion in forums and affinity groups within the organizations and beyond; these have been some of the motives of these initiatives. Efforts at gender-agnostic terminology, tools and opportunities are commendable here. Some women empowerment initiatives have triggered constructive legislation as well.

Ever since conception, these initiatives in organizations have had an incrementally beneficial effect on the industry and the community at large, which makes it all the more important to optimize these efforts and incorporate them into the DNA of the modern organization. Through our study, we delve deeper into the factors of success of women empowerment in major global infrastructural organizations, and the magnitude of effect these have on predictors of success of such initiatives. The present study, through analysis of factors or determinants of success of women

\footnotetext{
Revised Manuscript Received on September 10, 2019.

Deepika Pandita, Asst. Prof, SIBM Pune, Symbiosis International University, Pune, Maharashtra, India.

(Email: deepikapandita@ sibmpune.edu.in)

Hemendra Shribatho, Ultratech Cement Ltd, Mumbai, Maharashtra India.

(Email: hemendra.s@adityabirla.com)

Sampurna Ray, HR Manager, GE Research, Bangalore, Karnataka India

(Email: sampurna147@gmail.com)
}

empowerment initiatives, explores ways in which women empowerment initiatives may be optimized and built for success.

\section{OBJECTIVE OF THE STUDY}

- To analyse the drivers of women engagement practices by the organizations and its association with the performance of the women employees

- To analyse the changing aspects of women empowerment in organizations and measuring their engagement at work

- To recommend a framework to industry practitioners and policy-makers to implement effective and impactful women empowerment initiatives

\section{LITERATURE REVIEW}

In the context of social change and socially relevant work, the concept of women empowerment has a long history. In the 1970s, feminist consciousness-raising and collective action were prompted. The 1980s and 1990s saw women empowerment become more comprehensible as a radical approach concerned with transforming power relations in favour of women's rights and greater equality between women and men (Batliwala, 1993,2007). In documentations, women empowerment was a beacon for changes in consciousness and symbolic of collective power. It was recognized that the empowerment of women was not an advantage or privilege that could be bestowed by others, but instead, was sought out and demanded by oneself. Women empowerment in its nascent stages concerned recognizing inequalities in power and dynamics, asserting the right to certain things in equal measure as men and making efforts at bringing about structural changes in favour of greater equality (Batliwala, 1993; Kabeer, 1994; Rowlands, 1997; Sen, 1997).

Just as other initiatives aimed at empowerment do, women empowerment initiatives, have a psychological impact on the participants. This propagates as an increased efficacy and engagement at the workplace. This logically translates to the organization's success (Watkins, C., Hart, P. L., \& Mareno, N. 2016). The medium of action in such cases have been conclusively proven in several instances to be psychological.

Intuitively, structural empowerment has been shown to elevate existing levels of job satisfaction and productivity and this has been attributed to the induced feelings of psychological empowerment (Laschinger et al, 2004). The

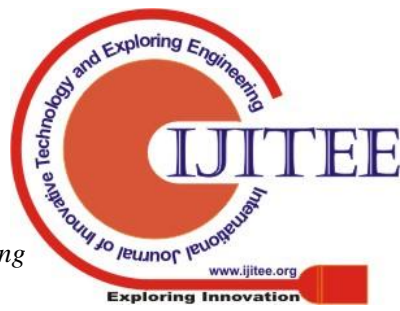


mechanism of action in these cases have been largely psychosomatic, in the positive sense of the word. The study mentions that "fostering environments that enhance perceptions of empowerment can have enduring positive effects on employees", indicating that perceptions of empowerment may have lasting positive effects just like been seen to reduce the likelihood of unfavourable mental

The path to empowering women may be interpreted as a literal path, a journey the participants are to make. The organization, in such cases, must therefore, clear obstacles from commonly travelled paths; support stopping places for women to reflect on their journeys and restart their journey with vigour, provide guidance in the form of route-maps, encouragement and the company of others; and sustenance in the form of knowledge for navigating the path to empowerment. Looking at the various dimensions of empowerment opens us up to possibilities and approaches in which the women in our workforce may be enabled holistically. Only with an increased understanding of the relational dynamics of power and positive change at various levels in the organization over time can we design effective and impactful empowerment initiatives (Cornwall 2016).

The perception of being empowered has been seen to have an impact on heightened job satisfaction, organizational commitment and ease of retention of female employees. Irrefutable causal associations have been established along these lines as well (Laschinger et al, 2009). One can only imagine how incredibly instrumental actual empowerment would be, if perceived empowerment has such positive impacts on organizational commitment and job satisfaction.

The digital era has ushered in changes that have eased and aided initiatives in general and women empowerment to be specific. The practices of blogging, participation in online affinity groups or forums, and using an online interaction platform are some of the means by which organizations have been leveraging technology to empower women and other groups (Shirazi, 2015). Almost every major multinational organization actively provides and encourages the use of digital platforms for communication and interaction. Surprisingly, leisure has also been mentioned as an indicator of empowerment of women in organizations (Green, 2015), more specifically that, how women spend time for leisure marks their levels of empowerment and engagement.

Unconventional methods are the norm now, with organizations implementing curated and customized initiatives to cater to their employees and clientele. In spite of the fact that organizations have been implementing women empowerment initiatives increasingly often in recent years, there is a gap in terms of formal body of work on the same. There is a need for studies following these organizations to examine the impact and future of these initiatives and the benefits other organizations may reap by following the trendsetters.

Women empowerment indicators in the society could be women's capacity to make arranged life choices or feel safe on the internet just as in daily life or the workplace (Kumar, 2017). The Worldwide Gender Gap Report from the World Economic Forum last year ranked Asia 114th away from actual empowerment. This psychological empowerment has health conditions (Hochwälder, 2015).

134 international locations for inequality between men and women. The study included information on economy, state policies, health, along with education. On equivalent economic prospects and women's participation within the labour force, India placed 127 th and 122nd respectively in the report. Women employment, both in rural and urban areas is really low compared to men, but the disparity is glaring when compared to other developed economies of the world.

In spite of training and skilling initiatives, females are lagging behind males in terms of literacy, skills and hence, empowerment (Kaur \& Singh, 2017). Education, training and skilling initiatives, such as the ones currently active in India, have the potential to be one of the strongest measures for empowering women in the society. These will aid in cutting down inequalities at early stages. A neglected focus area, empowering women through education and skilling will result in equal opportunities, social, legal and economic rights being provided to women.

Women empowerment is fascinating and a worthwhile cause, and for this very reason it has captured the interest of the Government as well as non-government agencies, social scientists, social activists, academicians and researchers throughout the world and more so in developing countries like India. In order to offset the sufferings of Indian women, many schemes/ programmes have been conceived and implemented by the Government from time to time. These initiatives in the public sector are aimed at the development of self along with collective efficaciousness (Bose, 2016).

The women in developing nations are not as empowered as their counterparts and contemporaries in developed economies. High youth unemployment along with early marital commitments and childbearing have added grief to the already woeful circumstances. Empowering women financially and socially in developing nations by providing them with professional and soft skills may help overcome their disadvantaged state (Oriana Bandiera, 2014).

\section{RESEARCH METHODOLOGY}

For this study, we used a combination of primary research (through structured interviews and literature review analysis) and additional review of contemporary women empowerment initiatives using a case study approach. We aimed to seek parity in the empowerment initiatives celebrated for their success and the initiatives that were identified as empowering by our respondents, so that we may arrive at determinants and predictors for success of these initiatives.

Our findings are derived from some in-depth interviews of 50 Indian women, who have been associated for varying durations with various infrastructural organizations such as L \& T Infrastructure, Reliance Infrastructure, GVK Group, Punj Lloyd Ultratech Cement Ltd, Lafarge Ltd, Lodha Group of Companies, ACC Group and Kalpataru Group. These women workforce were asked 15 questions in a structured interview in person, about women empowerment initiatives in their organizations. Following this information

Published By: 
gathering, we attempted to arrive at the factors driving a successful initiative, in the minds and according to the perception of the respondents.

After analyzing the responses to the questions, women empowerment initiatives were categorized into 4 principal factors which drove the success of the initiatives, which are as follows:

i. If the initiative(s) made women connect with each other \& increase belongingness

ii. If the initiative(s) were socially relevant and satisfied a social cause or a societal need

iii. If the initiative(s) were personally relevant to the women involved, furthered their ambitions \& broadened their opportunities

iv. If the initiative(s) made the women feel adequately empowered

We take a Case Study approach by analyzing numerous initiatives by these companies and practices by several organizations and assessing how these organizations continue to engage women at the workplace and beyond. This study also proposes a model to assist industry practitioners and policy makers in designing and implementing successful women empowerment initiatives.

\section{FINDINGS \& RESULTS}

Our information-gathering and analyses brought to light a few observations that deserve a mention here.

Female employees have traditionally represented a small percentage of the total workforce in the cement sector. To change this representation and make the workforce more gender diverse, Ultratech have institutionalized a host of women-friendly initiatives. The Women Empowerment \& Engagement (WEE) initiative at UltraTech works on the issues of importance for the women employees. It also includes a WEE community - an intranet based forum for women employees of UltraTech. The comprehensive Maternity Support Programme provides options and choices to female employees, so that they can effectively manage the maternity phase and return to work in a seamless manner. The maternity programme is a bouquet of benefits available to full-time Management cadre women employees. It includes maternity leave, mediclaim coverage, prenatal support through 'Healthy Pregnancy Programme', phaseback programme to support the returning mothers and emotional assistance support through the 'World of Women Network'.

At L \& T Infrastructure they believe in gender equality and aim to increase the number of women in their workforce. They initiated a programme called 'Renew', a platform that enables women professionals to re-enter the corporate world after a career break. Any woman on a career break is eligible, and those applying will be evaluated as per the current employment criterion. L\&T has a redressal system to handle complaints from female employees and it is covered under Protection of Women's Rights at Workplace Policy. The company has constituted apex and regional complaints committees to address cases of sexual harassment at the workplace, if any.

Lafarge has the approach that guides consistent action planning takes into account the actions that include the development of programs with a focus on women in operations, a roll-out of work flexibility options, and global diversity and inclusion training at all management levels (focusing on gender balance awareness and unconscious bias). Lafarge is moving ahead with gender equality management programs, working with independent partners Economic Dividends for Gender Equality (EDGE) to achieve progressive objectives. By moving ahead on gender diversity they will develop a culture of inclusivity and improve diversity generally.

The Lodha group for instance as a part of CSR measure conduct various training and placement activities. The Lodha foundation has partnered with various training and placement agencies to achieve the dual objective of vocational training and assisting employment for women. As part of the initiative, women get placed in housekeeping agencies and provide service as housemaids, cooks etc. while being a part of an organized workforce. The Lodha Foundation has conceptualized Self-Help Groups (SHG) that mobilises over 300 women through SHGs. These groups undertake regular savings and are involved in various social initiatives for the women.

\section{RECOMMENDATIONS}

Following are some of the recommendations that have prompted organizations to consider women empowerment seriously like firstly, In the workplace, women empowerment is indispensable for promoting a healthy workplace environment conducive to productive work for all employees irrespective of gender. The women-focused initiatives help women to develop and grow through education, grooming, skill development, career advancement, and financial self-sufficiency. Visible women empowerment efforts not only enable and strengthen the female employees but also ensure that other employees have an understanding of and sympathy with the cause, Secondly, Women empowerment efforts outside of or not limited to the organization are a boon to the community and to the world at large. This ensures that women are not denied resources, their progress is not hindered and that their socioeconomic development continues. Women are provided not only with facilities and resources, but also with knowledge and financial assistance for entrepreneurship and selfsustenance. Thirdly, some organizations have taken up women empowerment agendas so as to reform their image in the eyes of their consumers, customers or the public at large. These are typically organizations whose businesses (or products resulting from whose businesses) have harmful side effects for the environment, ecosystems or for people. These organizations have decided to do their part to contribute towards the well-being of its stakeholders (including the community) and women empowerment, being the need of the hour, is an entirely just and valid cause. Finally, Organizations have invested heavily in women empowerment sometimes as a part of their business as well. For instance, when incorporating women into the value chain or when employing women (directly or indirectly) and providing them with sustainable livelihoods. In such

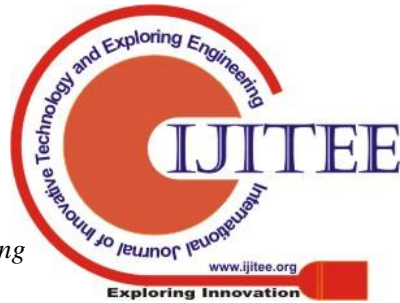


situations, women empowerment has a clear visible business case and translates directly to financial returns for the host organization

\section{CONCLUSION}

The paper ponders on four variables that are Connectedness, Acceptance, Relevance, and Engagement as the drivers for women empowerment. Companies have to give their women employees the liberty to make their work exciting and create an environment for having an engaged work life. Women employees are key to any organization and if they are not empowered and enabled, a sense of disengagement may set in. Organization and employees are both dependent on each other to fulfil their goals and objectives. Therefore, initiatives of women empowerment should not be a one-time exercise but it should be integrated in the culture of the company. The process of engaging the women employees should be continuous. Organizations today should proactively fulfil women employees' expectations by paving newer avenues of opportunities in the organization and thus, creating an impact on the engagement, satisfaction and performance of women employees, which directly translates to the organization's performance.

\section{LIMITATIONS}

This study has highlighted four variables that are Connectedness, Acceptance, Relevance, and Engagement as the drivers for women empowerment thus engaging the women workforce. There may be many more dimensions explored for deeper understanding of women empowerment practices. However, the study is conceptual in nature and largely draws from existing literature and some focussed group interviews. Nevertheless, since this is a qualitative study one can test this model by collecting primary data and conducting an empirical analysis.

\section{REFERENCES}

1. Armstrong, M. E., Green, J., Reeves, G. K., Beral, V., \& Cairns, B. J. (2015). Excessive Physical Activity may not be as Beneficial as Moderate Physical Activity for Vascular Disease Risk in UK Women. International Journal of Epidemiology, 44(suppl_1), i127-i127.

2. Bandiera, O., Burgess, R., Goldstein, M., Buehren, N., Gulesci, S., Rasul, I., \& Sulaiman, M. (2014). Women's empowerment in action: evidence from a randomized control trial in Africa.

3. Bose, P. (2016). Assessment of Women Self Help Groups with Reference to Socio-Economic and technological performance in Surguja Dist (CG) (Doctoral dissertation, Indira Gandhi Krishi Vishwavidyalaya, Raipur).

4. Cornwall, A. (2016) Women's Empowerment: What Works? J. Int. Dev., 28: 342-359. doi: 10.1002/jid.3210.

5. De Nmark, F. L. (1993), Women, Leadership, and Empowerment. Psychology of Women Quarterly, 17: 343-356. doi:10.1111/j.1471-6402. 1993.tb00491.x

6. Hochwälder, J. (2015). Test of Antonovsky's postulate: High sense of coherence helps people avoid negative life events. Psychological reports, 116(2), 363-376.

7. Kaur, A., \& Singh, N. (2017). Changing Behavior of Society towards women empowerment. CLEAR International Journal of Research in Commerce \& Management, 8(2).
8. Kumar, P. (2017). Traditional Knowledge Related Intellectual Property Rights: Empowering Women.

9. Laschinger, H. K. S., Finegan, J. E., Shamian, J. and Wilk, P. (2004). A longitudinal analysis of the impact of workplace empowerment on work satisfaction. J. Organization. Behavoir, 25: 527-545. doi:10.1002/job.256

10. Laschinger, H. K. S., Wong, C. A., Cummings, G. G., \& Grau, A. L. (2014). Resonant leadership and workplace empowerment: The value of positive organizational cultures in reducing workplace incivility. Nursing Economics, 32(1), 5 .

11. Psychological empowerment at the workplace as a predictor of ill health. Jacek Hochwälder, Agneta Bergsten Brucefors (2005).

12. Psychological Empowerment in the Workplace: Dimensions, Measurement, and Validation. Gretchen M. Spreitzer. Academy of Management Journal. October 1, 1995 vol. 38 no. 5 1442-1465

13. Reshetova, O., Ardon, P., Wainaiana, M., Batliwala, S., \& Gupta, S. (2014). Doing It Right, Doing It Well. Building the Capacity of Women's Funds and Their Partners to Assess Results and Impacts. INWF/Association for Women's Rights in Development (AWID).

14. Shirazi, M., Shirazi, A., \& Bloom, J. (2015). Developing a culturally competent faith-based framework to promote breast cancer screening among Afghan immigrant women. Journal of religion and health, 54(1), 153-159.

15. Spence Laschinger, H. K., Leiter, M., Day, A. And Gilin, D. (2009). Workplace empowerment, incivility, and burnout: impact on staff nurse recruitment and retention outcomes. Journal of Nursing Management, 17: 302-311. doi:10.1111/j.1365-2834.2009. 00999.x

16. Watkins, C., Hart, P. L., \& Mareno, N. (2016). The effect of preceptor role effectiveness on newly licensed registered nurses' perceived psychological empowerment and professional autonomy. Nurse education in practice, $17,36-42$

17. 'Women Doing Friendship': an analysis of women's leisure as a site of identity construction, empowerment and resistance. Eileen Green. Leisure Studies Vol. 17, Iss. 3,1998

\section{WEB REFERENCES}

18. Aditya Aluminium's initiative towards Women Empowerment. India CSR Network. April 18, 2017. Retrieved from https://indiacsr.in/aditya-aluminiumsinitiative-towards-women-empowerment/

19. https://www.infrabazaar.com/blog/Top-10-InfrastructureCompanies-of-India/93

\section{AUTHORS PROFILE}

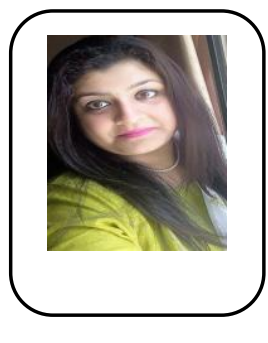

Deepika Pandita, Ph.D. is an Assistan Professor in Symbiosis Institute of Busines Management Pune at Symbiosis International University. She teaches post graduate and Executive MBA courses in the area of human resources, organizational learning and leadership and talent management. Dr. Pandita`s research focuses on talent management, leadership, and learning within organizations. She has published in reputed 
journals: European Business Review, Industrial and Commercial Training Journal and Social and Behaviour Sciences Journal. She has a graduate degree in Management and post graduate degree in Management and Human Resources. Her PhD is in the area of Talent Management and Employee Engagement. She has been in the human resources field both professionally and academically for more than 12 years.

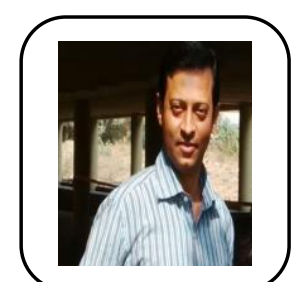

Mr. Hemendra Shribatho is working as Zonal Manager Technical Services Key Accounts at UltraTech Cement Ltd, Mumbai. He is BE Civil, DBM \& DMM with an overall work experience of $25 \mathrm{yrs}$ in field of construction industry. He is also active part of Construction Supervisor Course by American Concrete Institute- Mumbai Chapter. He is actively engaged in Infrastructure project segment for over 16 years.

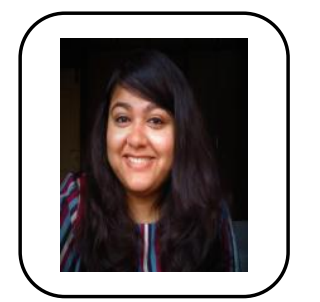

Sampurna Ray is in the Human Resources Leadership Program at GE, and in that capacity is an HR Manager with GE Research. She has experience in Talent Development \& Strategy, HR Analytics, Business Partnership and Instructional Design. As an intern with GE in their Organization \& Talent Development team, worked on People Leader effectiveness \& analytics. She graduated from Symbiosis Institute of Business Management, Pune, India with a Master's in Business Administration (HR). Her areas of interest include HR Analytics and Design, and she's an amateur food photographer. 